\title{
Pathofysiologie van lipopolysaccharide geïnduceerde inflammatoire respons bij vogels
}

\section{Pathophysiology of lipopolysaccharide-induced inflammatory response in birds}

\author{
${ }^{1}$ R. Houben, ${ }^{1}$ S. Croubels, ${ }^{1,3}$ A. Watteyn, ${ }^{1,2}$ G. Antonissen \\ ${ }^{1}$ Vakgroep Farmacologie, Toxicologie en Biochemie, \\ ${ }^{2}$ Vakgroep Pathologie, Bacteriologie en Pluimveeziekten, \\ Faculteit Diergeneeskunde, Universiteit Gent, Salisburylaan 133, 9820 Merelbeke, België \\ ${ }^{3}$ Vetpharm, Noordkaai 24, 8870 Izegem, België
}

Gunther.Antonissen@UGent.be

\section{AMENVATTING}

Inflammatie is een beschermende respons op infectie en/of weefselschade die gepaard gaat met de migratie van immuuncellen en mediatoren van de circulatie naar het betreffende weefsel. Deze respons dient om de initiële noxe (onder andere lipopolysaccharide of LPS) te verwijderen en genezing en herstel van het beschadigde weefsel te bekomen. LPS is een onderdeel van de buitenste celmembraan van gramnegatieve bacteriën dat pro-inflammatoire eigenschappen heeft en na toediening bij vogels een ontstekingsreactie teweegbrengt. Deze ontstekingsreactie gaat gepaard met onder andere veranderingen in lichaamstemperatuur, de productie van pro-inflammatoire cytokinen en vorming van acutefase-eiwitten, leukocytose en ziektegedrag. In welke mate elk van deze symptomen aanwezig is bij vogels hangt af van de vogelsoort. Bovendien zijn er verschillen met zoogdieren. De karakteristieken en pathofysiologische gevolgen van een ontstekingsreactie worden vaak bestudeerd in LPS-inflammatiemodellen. Deze inflammatiemodellen kunnen vervolgens toegepast worden in farmacodynamiekstudies om het klinisch effect van anti-inflammatoire geneesmiddelen, zoals niet-steroïdale ontstekingsremmers (NSAIDs) te beoordelen. In dit artikel wordt een overzicht gegeven van de LPS-geïnduceerde inflammatoire respons bij vogels.

\section{ABSTRACT}

Inflammation is a protective response to infection and/or tissue damage and it induces migration of immune cells and mediators of immune response from the circulation to the infected and/or damaged tissue. This response will remove the initial noxe (e.g. lipopolysaccharide or LPS) and tissue healing will be stimulated. LPS is part of the outer membrane of gram-negative bacteria and causes an inflammatory response in birds due to its proinflammatory properties. As a result to this inflammatory response, birds develop a change in body temperature, increased production of proinflammatory cytokines and acute phase proteins, show leukocytosis and sickness behavior. The magnitude of these symptoms in birds depends on the bird species and differs from the symptoms in mammals. The characteristics and pathophysiology of an inflammatory response are frequently studied using LPS inflammation models. These models can further be applied for pharmacodynamic studies to assess the clinical effect of different anti-inflammatory drugs, such as non-steroidal anti-inflammatory drugs or NSAIDs. In this paper, an overview of the LPS-induced inflammatory response in birds is given.

\section{INLEIDING}

Gramnegatieve bacteriën, zoals Escherichia coli (E. coli) en Salmonella spp., bestaan uit een cytoplasma omgeven door een membraan die opgebouwd is uit een buitenmembraan, een plasmamembraan en ertussen een peptidoglycaanlaag die zorgt voor de stevigheid van de cel (Figuur 1). De buitenmembraan bevat twee lagen, waarvan de binnenste laag bestaat uit glycerofosfolipiden en de buitenste laag voornamelijk uit lipopolysacchariden (LPS) en enkele fosfolipiden (Wright en Kangeasaki, 1971). Daarnaast bevat de buitenmembraan lipoproteïnen, porineproteinen en membraanproteïnen die verankerd zijn in de onderliggende peptidoglycaanlaag. Deze membraan speelt een rol in het transport van nutriënten vanuit 


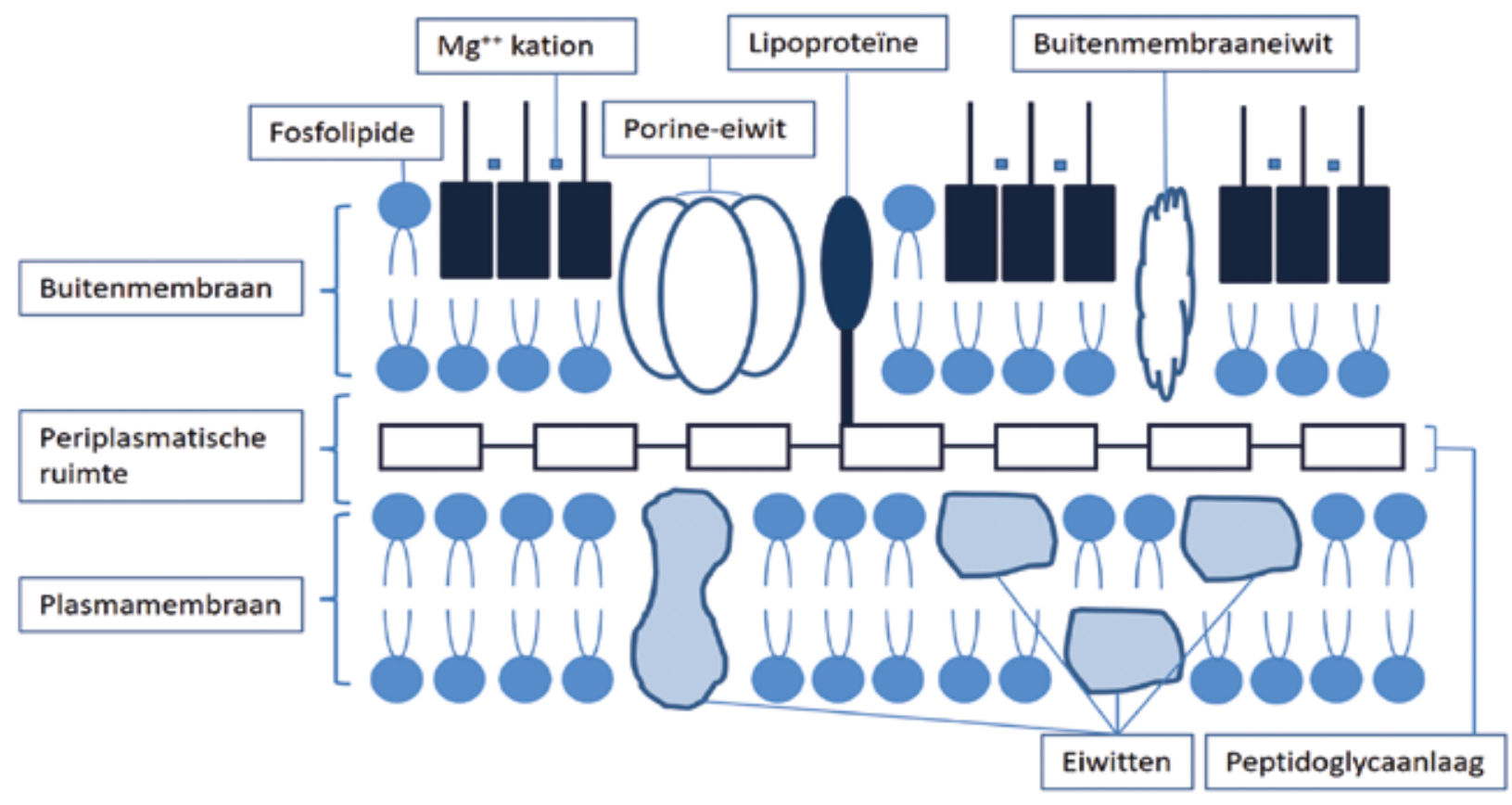

Figuur 1. Schematische illustratie van de buitenmembraan, celwand en peptidoglycaanlaag van een gramnegatieve bacterie (naar Todar, 2006).

de omgeving naar de bacterie en de fysiologische en pathofysiologische interacties tussen bacterie en gastheercellen. Tevens kan deze membraan de intrede van toxische stoffen inhiberen, zoals antimicrobiële middelen (Rietschel et al., 1994; Holst, 2007). De peptidoglycaanlaag is opgebouwd uit verschillende ketens bestaande uit afwisselend $\mathrm{N}$-acetylglucosamine- en $\mathrm{N}$-acetylmuraminezuur-moleculen die onderling worden verbonden via tetrapeptiden. Deze tetrapeptiden zijn opgebouwd uit L-alanine, D-glutamaat, diaminopimelinezuur en D-alanine. De plasmamembraan bestaat uit fosfolipiden en proteïnen (Todar, 2006).

LPS is een endotoxine dat een sterke immuunrespons kan veroorzaken bij mens en dier. Het is een glycolipide dat bestaat uit drie covalent verbonden delen: het lipide A, een kern met polysacchariden en het O-antigeen (Figuur 2). De LPS-molecule is verankerd in de buitenmembraan van de gramnegatieve bacterie via het lipide A-domein (Raetz et al., 1988; Rietschel et al., 1993; Rietschel et al., 1994; Holst, 2007) (Figuur 2). Lipide A is een lipide dat bestaat uit verzadigde vetzuren en gefosforyleerd N-acetylglucosamine (Lüderitz et al., 1982; Todar, 2006). Dit lipide vormt het hydrofobe domein van de LPS-molecule en wekt een immuunrespons op bij de gastheer (Holst, 2007). Het kerngedeelte is een polysaccharide dat bestaat uit een korte suikerketen, die onder andere heptose en 2-keto-3-deoxyoctoninezuur bevat en het lipide $\mathrm{A}$ en $\mathrm{O}$-antigeen verbindt. Het $\mathrm{O}$-antigeen is een polysaccharide dat bestaat uit herhalende subeenheden van oligosacchariden. Het vormt het hydrofiele domein van de LPS-molecule en heeft een sterk antigene werking (Rietschel et al., 1994; Todar, 2006).

LPS heeft pro-inflammatoire eigenschappen en brengt een ontstekingsreactie op gang die gepaard gaat met immunologische veranderingen (Skarnes et al., 1981; Morimoto et al., 1987; Haudek et al., 2002). Inflammatie is een beschermende respons op infectie en/of weefselschade die gepaard gaat met de migratie van immuuncellen en mediatoren naar het betreffende weefsel. Deze respons dient om de initiële noxe te verwijderen en genezing en herstel van het beschadigde weefsel te bekomen (Kumar et al., 2015, Lees et al., 1991). In dit artikel wordt een overzicht gegeven van de LPS-geïnduceerde inflammatoire respons bij vogels.

\section{INFLAMMATOIRE RESPONS OP LPS}

Bij de LPS-geïnduceerde ontstekingsreactie is er interactie tussen het lipide A-domein van de LPSmolecule en "LPS binding protein" (LBP). LBP is een serumglycoproteïne dat wordt geproduceerd door hepatocyten en in verhoogde concentratie aanwezig is tijdens de ontstekingsreactie (Tobias et al., 1986; Ramadori et al., 1990; Schumann et al., 1990). Deze interactie leidt tot activatie van gastheercellen, waaronder mononucleaire cellen, polymorfonucleaire cellen, endotheelcellen en trombocyten (Rietschel et al., 1994). LBP bindt aan LPS en interageert met "cluster of differentiation 14" (CD14), dat bestaat in een oplosbare vorm en een membraangebonden vorm die aanwezig is op het celoppervlak van mononucleaire cellen. Het gevormde CD14:LPS complex zorgt in membraangebonden vorm voor de activatie van de betreffende cel en in oplosbare vorm voor de activatie van cellen die geen membraangebonden CD14 bevat- 


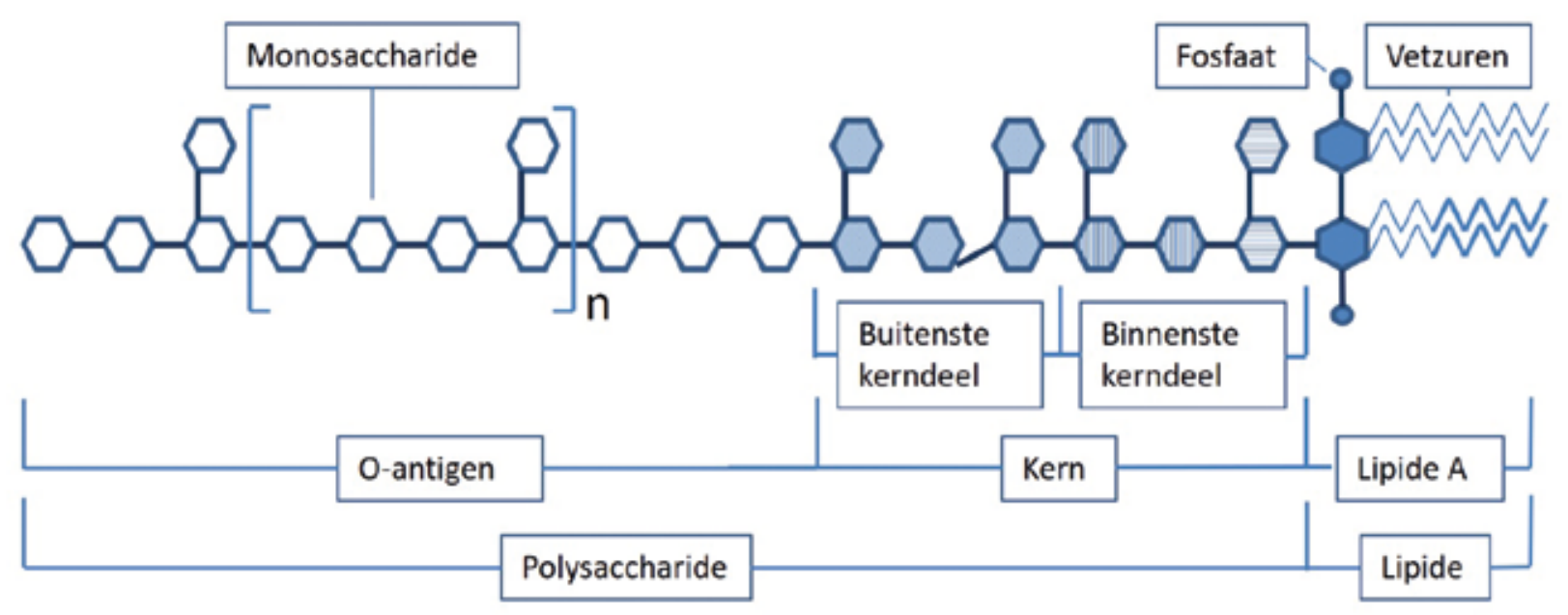

Figuur 2. Schematische voorstelling van de structuur van LPS (naar Tobias et al., 1999).

ten (Mayeux, 1997; Moore en Barton, 1998; Sass et al., 2002; Jerala, 2007). Deze activatie wordt gemedieerd door de interactie tussen CD14 en "toll-like receptor 4" (TLR-4) en leidt zo tot de activatie van "nuclear factor $\kappa \mathrm{B}$ " (NFkB) (Dil en Qureschi, 2002; Doyle en O'Neill, 2006). De activatie van heterofielen door LPS gebeurt bij kippen eveneens door middel van LBP, CD14 en TLR-4 (Kogut et al., 2005). CD14, dat bij zoogdieren een glycosylfosfatidylinositol-geankerd eiwit is, is bij kippen echter een transmembranair eiwit dat minder mobiel is in de celmembraan. Hierdoor reageren kippen minder sterk op LPS-toediening dan zoogdieren (De Boever et al., 2009; Wu et al., 2009). NFkB fungeert als transcriptiefactor voor genen die coderen voor pro-inflammatoire cytokinen, zoals "tumor necrosis factor $\alpha$ " (TNF- $\alpha$ ), interleukine 1 (IL-1), interleukine 6 (IL-6) en interferon $\gamma($ IFN- $\gamma$ ) (Heinrich et al., 1990; Baeuerle en Henkel, 1994). TNF- $\alpha$ wordt vrijgesteld door onder andere monocyten, macrofagen, T-cellen en B-cellen en stimuleert de productie van IL-1 $\beta$ en IL-6 (Witkamp en Monshouwer, 2000). IL-1, IL-6 en TNF- $\alpha$ zorgen onder andere voor koortsinductie, verhoogde synthese van acutefase-eiwitten in de lever, differentiatie van immuuncellen, stijging van het serumgehalte van cortisol, cortisone en bij vogels corticosterone en de activatie van het vasculaire endotheel (Durum et al., 1990; Schneider et al., 2001). IFN- $\gamma$, IL-1 $\beta$ en IL10 zijn aangetoond bij de kip (Jakowlew et al., 1988; Jakowlew et al., 1990; Digby en Lowenthal, 1995) en hebben een gelijkaardige functie als bij zoogdieren (Lillehoj et al., 1992; Song et al., 1997; Weining et al., 1998; Rothwell et al., 2004). In een in-vitrostudie werd de productie van TNF- $\alpha$ aangetoond bij macrofagen afkomstig van kippen geïnfecteerd met Eimeria maxima en E. tenella (Byrnes et al., 1992). Daarnaast werd bij de kip ook de aanwezigheid aangetoond van de TNF- $\alpha$ receptor en TNF-like ligand 1A (TL1A), wat een gelijkaardige activiteit heeft als TNF- $\alpha$ (Rau- tenschlein et al., 1999; Koskela et al., 2004; Schneider et al., 2004; Goetz et al., 2004; Kaiser et al., 2005; Hong et al., 2006; De Boever et al., 2009). TL1A wordt onder andere geproduceerd door lymfocyten in de milt, lever en het darmepitheel en stimuleert de synthese van IL-1 $\beta$, IL- 6 en IFN- $\gamma$. Daarnaast zorgt het voor een verhoogde vrijstelling van induceerbaar stikstofoxidesynthase (iNOS) en cyclooxygenase 2 (COX-2) (Geller et al., 1993; Park et al., 2007; Takimoto et al., 2008). De verhoogde productie van iNOS zorgt voor de ontwikkeling van hypotensie (De Boever et al., 2009). De ontstekingsreactie gaat eveneens gepaard met hypocholesterolemie als gevolg van een verandering in het cholesterol- en lipoproteïnemetabolisme ter hoogte van de lever (Kushner, 1982). De belangrijkste kenmerken van de ontstekingsreactie zijn verandering in lichaamstemperatuur, de productie van pro-inflammatoire cytokinen en hepatische acutefase-eiwitten, leukocytose, activatie van de hypothalamo-hypofysaire as, onderdrukking van de hypothalamo-hypofyso-gonadale as en het optreden van ziektegedrag (Klasing, 2004; Owen-Ashley en Wingfield, 2007). In Tabel 1 wordt een overzicht gegeven van de gepubliceerde in-vivo-en -in-vitro-LPSinflammatiemodellen bij vogels.

\section{Veranderingen in lichaamstemperatuur}

Koorts is het gevolg van de cascade die in gang wordt gezet door exogene pyrogenen, zoals LPS, die leukocyten aanzetten tot een verhoogde vrijstelling van IL-1 $\beta$ en TL1A. Dit zijn endogene pyrogenen die onder andere zorgen voor een verhoogde expressie van $\mathrm{COX}$ en de synthese van prostaglandine $\mathrm{E}_{2}$ $\left(\mathrm{PGE}_{2}\right)$ (Heinrich et al., 1990; Kumar et al., 2015). $\mathrm{PGE}_{2}$ zorgt ter hoogte van de hypothalamus voor een verhoogde productie van neurotransmitters die de setpoint voor lichaamstemperatuur verhogen (Netea et al., 2000). Een verhoogde lichaamstemperatuur sti- 


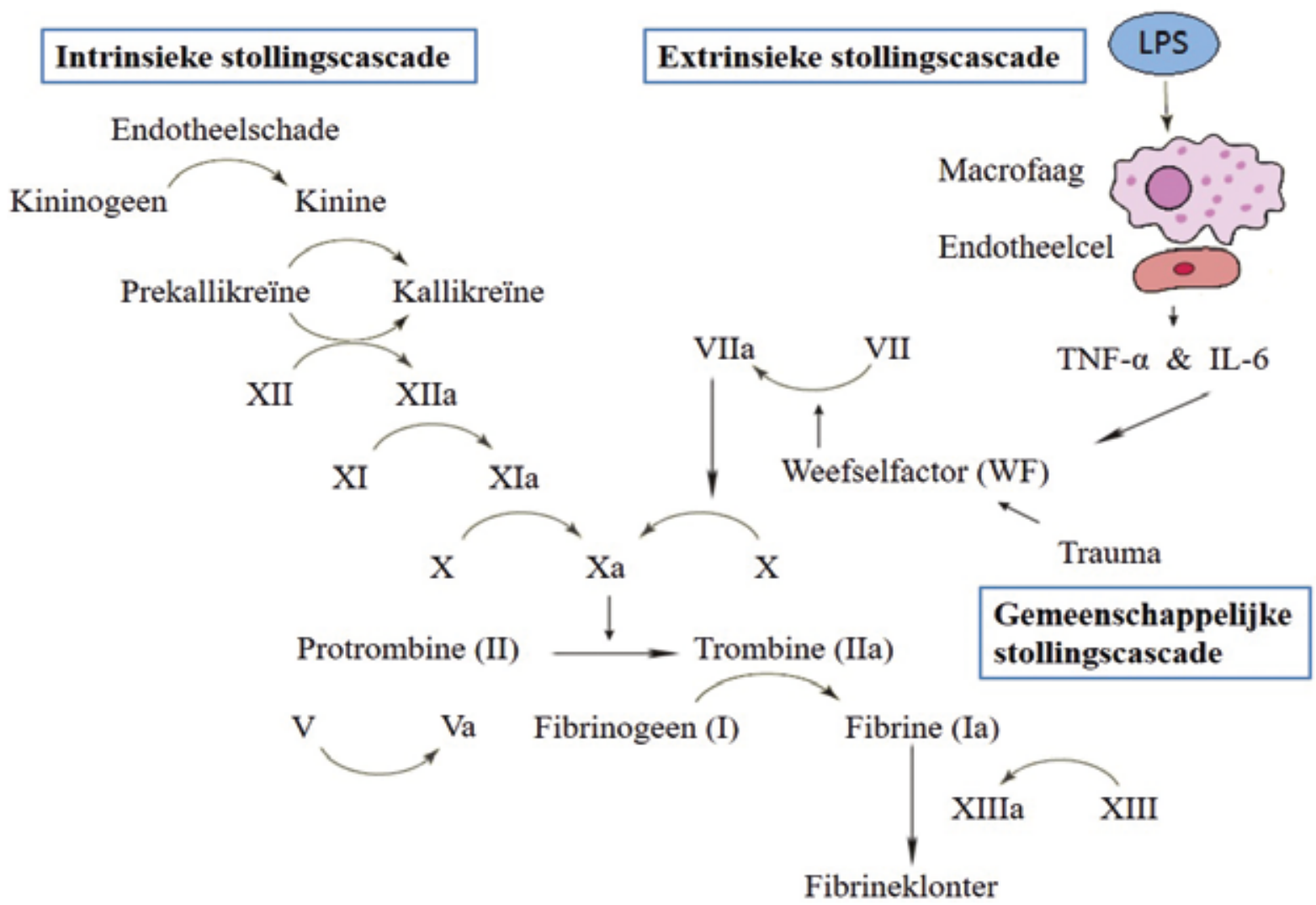

Figuur 3. Factoren betrokken bij de intrinsieke en extrinsieke stollingscascade en hun rol bij de vorming van een bloedklonter (naar Karima et al., 1999).

muleert de synthese van acutefase-eiwitten. Daarnaast stimuleert het de activiteit van heterofielen en macrofagen, zorgt het voor ijzersequestratie en inhibeert het de bacteriële groei (Netea et al., 2000). Het effect van pyrogenen op de lichaamstemperatuur is afhankelijk van de balans tussen productie en verlies van warmte, die beide beïnvloed worden door de lichaamsgrootte en omgevingstemperatuur (Kluger, 1986). Na experimentele toediening van LPS werd er in een studie bij zebravinken (Taeniopygia guttata) en andere Passeriformen hypothermie vastgesteld (Burness et al., 2010), en bij kippen, duiven, eenden en Japanse kwartels (Coturnix japonica) hyperthermie (Baert et al., 2005a; Owen-Ashley et al., 2006; De Boever et al., 2010). Deze hyperthermie wordt bij de kippen en duiven voorafgegaan door een korte periode van hypothermie. Bij herhaalde toediening van LPS bij kippen blijft hypothermie zelfs volledig uit (De Boever et al., 2008). De sterk uitgesproken hypothermie die optreedt bij Passeriformen wordt veroorzaakt door een hoge lichaamsoppervlakte-volumeratio, waardoor er relatief meer warmteverlies optreedt dan bij grotere vogels en de thermoregulatie moeilijker verloopt (Owen-Ashley en Wingfield, 2007). Daarnaast is de gemiddelde lichaamstemperatuur van vogels relatief hoog $\left(41^{\circ} \mathrm{C}\right)$, waardoor elke bijkomende temperatuur- verhoging door een verhoogd metabolisme moeilijk is, aangezien het metabolisme voor elke stijging van de lichaamstemperatuur met $1^{\circ} \mathrm{C}$ moet verhogen met $10 \%$ (Kluger, 1979; Owen-Ashley en Wingfield, 2007). Knaagdieren met dezelfde lichaamsoppervlaktevolumeratio en een lagere gemiddelde lichaamstemperatuur $\left(36-37^{\circ} \mathrm{C}\right)$ zijn wel in staat om hyperthermie te ontwikkelen tijdens de ontstekingsreactie (OwenAshley en Wingfield, 2007).

Verschillende parameters hebben een invloed op de lichaamstemperatuur van vogels tijdens de ontstekingsreactie, zoals de leeftijd en het moment van de dag. Zo treedt er bij zebravinken hypothermie op na injectie van LPS gedurende de dag en hyperthermie na injectie van LPS gedurende de nacht. Dit kan verklaard worden door het feit dat de lichaamstemperatuur van deze vogels overdag hoger is en tevens toeneemt door warmteproductie tijdens activiteit, waardoor er een risico bestaat op oververhitting indien de vogels hyperthermie zouden ontwikkelen (SköldChiriac et al., 2015). Bij oververhitting wordt de lichaamstemperatuur dermate hoog dat er celnecrose, oedeem en mogelijk bloedingen optreden ter hoogte van onder andere de lever, het centrale zenuwstelsel, de nieren en de hartspier (Malamud et al., 1946; Gore en Isaacson, 1949; Fajardo, 1984). 's Nachts is de li- 
chaamstemperatuur van vogels lager, waardoor het risico op oververhitting lager is en bijgevolg hyperthermie ontwikkeld kan worden om infecties te bestrijden (Sköld-Chiriac et al., 2015). Ook de leeftijd van vogels beïnvloedt de verandering in lichaamstemperatuur tijdens de acutefaserespons. Bij kippen van één tot twee weken oud treedt er hypothermie op gevolgd door hyperthermie, terwijl kippen van drie tot acht weken oud direct hyperthermie ontwikkelen (Jones et al., 1983). Dit kan verklaard worden door de beperkte aanwezigheid van het thermoregulatievermogen bij zeer jonge kippen, waardoor hyperthermie minder efficiënt geïnduceerd wordt (Jones et al., 1983; Frafield en Kaplanski, 1998). Deze bevinding verschilt van die van De Boever et al. (2009) waarbij LPS-geïnduceerde hyperthermie bij kippen van drie en vijf weken oud wel werd voorafgegaan door een korte periode van hypothermie. Dantonio et al. (2016) toonden aan dat stikstofoxide (NO) eveneens een rol speelt in het mediëren van de lichaamstemperatuur tijdens de ontstekingsreactie bij vogels. Intramusculaire toediening van een NO-synthase-inhibitor (N-nitro-L-arginine methylester of L-NAME) aan vleeskippen van vijf dagen oud, die intramusculair LPS toegediend gekregen hadden, onderdrukte de thermogenese bij een omgevingstemperatuur die lager was dan de thermoneutrale zone voor deze dieren $\left(35-36^{\circ} \mathrm{C}\right)$. Dit leidde tot een versterkte hypothermiefase en een minder uitgesproken hyperthermiefase bij deze dieren. Bij een thermoneutrale omgevingstemperatuur werd de lichaamstemperatuur niet door L-NAME beïnvloed, wat aantoont dat NO perifeer inwerkt op de thermogenese en de centrale temperatuurregulatie niet medieert (Dantonio et al., 2016). Dit werd ook aangetoond bij ratten (Steiner et al., 2004). Het feit dat de $\mathrm{PGE}_{2-}$ concentratie in de hersenen evenmin wordt beïnvloed door L-NAME-injectie bevestigt deze theorie. Bij ratten stimuleert $\mathrm{NO}$ de thermogenese ter hoogte van het bruine vetweefsel door middel van vasodilatatie. Bij vogels is er geen bruin vetweefsel aanwezig, maar zou thermogenese worden bekomen via bepaalde mechanismen in de skeletspieren (Kluger, 1991; Nagashima et al., 1994; Steiner et al., 2001; Branco et al., 2014). Om na te gaan welke mechanismen dit precies zijn, is verder onderzoek noodzakelijk (Dantonio et al., 2016).

\section{Pro-inflammatoire cytokinen en acutefase-eiwitten}

In Tabel 1 wordt weergegeven welke cytokinen onderzocht werden in de beschikbare in-vitro-en -in-vivo-LPS-modellen bij vogels (mRNA-expressie en/of eiwitgehalte). Er wordt eveneens vermeld wanneer de maximale of piekconcentratie bereikt werd. De productie van pro-inflammatoire cytokinen leidt tevens tot een verhoogde productie van acutefase-eiwitten in de hepatocyten (Heinrich et al., 1990). Welke acutefaseeiwitten aanwezig zijn, is diersoortafhankelijk (Heinrich et al., 1990). De belangrijkste acutefase-eiwitten die in concentratie toenemen tijdens een inflamma- toire respons bij de kip zijn hemopexine, a1-zure glycoproteïne ( $\alpha 1-A G)$, ceruloplasmine, transferrine, fibronectine en serum amyloid A (Curtis en Butler, 1980; Nakamura et al., 1998; Takahashi et al., 1998; Chamanza et al., 1999; Barnes et al., 2002). Ceruloplasmine oxideert tweewaardig ijzer $\left(\mathrm{Fe}^{2+}\right)$ tot driewaardig ijzer $\left(\mathrm{Fe}^{3+}\right)$ en faciliteert zo het transport van ijzer door transferrine (Murata et al., 2004). Transferrine wordt geproduceerd als respons op de verhoogde vrijstelling van IL-6 (Xie et al., 2002). Het bindt ijzerionen $\left(\mathrm{Fe}^{3+}\right)$, zodat er minder ijzerionen beschikbaar zijn voor pathogenen en het moduleert de functies van macrofagen en heterofielen (Xie et al., 2002; Murata et al., 2004). De verhoogde productie van acutefaseeiwitten in de lever is het gevolg van een verhoogde activiteit van specifieke enzymen in de hepatocyten (Kushner et al., 1982). Daarnaast zorgen onder andere de toediening van LPS en het gewichtsverlies voor een verhoogd levermetabolisme. Dit heeft als gevolg dat het gewicht van de lever toeneemt (Koh, 1996; Sherwin en Sobenes, 1996; Bayyari et al., 1997; Xie et al., 2000).

\section{Leukocytose}

Leukocytose is het gevolg van een verhoogde vrijstelling van heterofielen uit de reservepool van het beenmerg veroorzaakt door de vrijstelling van "granulocyt-colony stimulating factor" (G-CSF) en granulocyt-macrofaag-CSF (GM-CSF) door macrofagen (Morrison en Ulevitch, 1978; Kogut et al., 1997; Kaiser et al., 2005). Deze heterofilie wordt bij kalkoenen voorafgegaan door een korte periode van leukopenie als gevolg van een daling van het aantal heterofielen in de circulatie door sequestratie in de bloedvaten van de longen en lever (Harmon, 1998; De Boever et al., 2009). Bij de kip werd eveneens leukopenie aangetoond die behalve door sequestratie van heterofielen in de longen ook het gevolg zou zijn van apoptose van de circulerende heterofielen (De Boever et al., 2009).

\section{Ziektegedrag}

Naast een verandering in lichaamstemperatuur, de productie van pro-inflammatoire cytokinen en acutefase-eiwitten en leukocytose zorgt de ontstekingsreactie voor gedragsveranderingen. Deze omvatten onder andere een verminderde activiteit en een verminderde voeder- en drinkwateropname met gewichtsverlies als gevolg. Het doel van deze gedragsveranderingen is om de energie die gebruikt wordt voor activiteiten die niet direct essentieel zijn voor overleving, zoals foerageren, groei en reproductie, te verminderen en de aanvoer van belangrijke nutriënten, zoals zink en ijzer voor de replicatie van bacteriën te beperken (Hart, 1988; Klasing, 1984; Langhans, 2000). Als de voedselopname echter te beperkt is, daalt het lichaamsgewicht sterk en kunnen er ziekte en cachexie optreden, waardoor de kans op overleving en herstel kleiner is (Plata-Salamán, 1996; 
Tabel 1. Overzicht van in-vitro en in-vivo-LPS-inflammatiemodellen bij vogels.

\begin{tabular}{|c|c|c|c|c|c|c|c|c|}
\hline LPS (sero)type & Dosering & $\begin{array}{l}\text { Vogelsoort/ } \\
\text { cel type }\end{array}$ & $\begin{array}{l}\text { Leef- } \\
\text { tijd }\end{array}$ & $\begin{array}{l}\text { Gewicht } \\
\text { (g) }\end{array}$ & $\begin{array}{l}\text { Toe- } \\
\text { diening }\end{array}$ & $\begin{array}{l}\text { Lichaams- } \\
\text { temperatuur }\end{array}$ & Cytokinen & Referentie \\
\hline E. coli $0127: \mathrm{B} 8$ & $1 \mathrm{mg} / \mathrm{dier}$ & vleeskip & $3 w$ & $700-900$ & IP & $\uparrow$ (piek 3u n.t.) & - & (Fraifeld et al., 1995) \\
\hline E. coli $0127: \mathrm{B} 8$ & $0,9 \mathrm{mg} / \mathrm{dier}$ & legkip & & - & IP & - & - & (Inoue et al., 1997) \\
\hline E. coli $0127: \mathrm{B} 8$ & $1 \mathrm{mg} / \mathrm{kg} \mathrm{LG}$ & vleeskip & $5 w$ & 1400 & IV & $\begin{array}{l}\uparrow(\text { piek } 2 u \text { n.t.) } \\
\text { bifasisch (1-5u/ 6-8u) }\end{array}$ & - & (Baert et al., 2005a,b) \\
\hline E. coli $0127: \mathrm{B} 8$ & $1 \mathrm{mg} / \mathrm{kg} \mathrm{LG}$ & vleeskip & $5 w$ & - & IV & $\uparrow_{\text {bifasisch }(3-5 u / 9-12 u)}$ & - & (Jones et al., 1981) \\
\hline \multirow[t]{2}{*}{ E. coli $0127: \mathrm{B} 8$} & \multirow[t]{2}{*}{$1 \mathrm{mg} / \mathrm{kg} \mathrm{LG}$} & \multirow[t]{2}{*}{ vleeskip } & $3 \mathrm{w}$ & - & IV & \multirow{2}{*}{$\begin{array}{l}\downarrow \text { (piek 1u n.t.) gevolgd } \\
\text { door } \uparrow \text { (piek 8u n.t.) } \\
\downarrow \text { gevolgd door } \uparrow\end{array}$} & $\uparrow$ IL-6 plasma & \multirow[t]{2}{*}{ (De Boever et al., 2008) } \\
\hline & & & $5 w$ & - & IV & & - & \\
\hline \multirow[t]{2}{*}{ E. coli $0127: \mathrm{B} 8$} & \multirow[t]{2}{*}{$2,5 \mathrm{mg} / \mathrm{kg} \mathrm{LG}$} & \multirow[t]{2}{*}{ vleeskip } & \multirow[t]{2}{*}{$5 w$} & \multirow[t]{2}{*}{-} & \multirow[t]{2}{*}{ IV } & \multirow[t]{2}{*}{$\begin{array}{l}\downarrow \text { (piek } 3 \text { u n.t.) gevolgd } \\
\text { door } \uparrow(\text { piek } 12 \text { u n.t.) }\end{array}$} & $\uparrow$ IL-6 plasma & \multirow[t]{2}{*}{ (De Boever et al., 2009) } \\
\hline & & & & & & & $\begin{array}{l}\uparrow \text { IL-1 } \beta \text { en IL-6- } \\
\text { expressie in heterofielen }\end{array}$ & \\
\hline E. coli $0127: \mathrm{B} 8$ & $2,5 \mathrm{mg} / \mathrm{kg} \mathrm{LG}$ & vleeskip & $5 w$ & 1270 & IV & $\uparrow$ (piek 12u n.t.) & $\begin{array}{l}\uparrow \text { IL-6 plasma } \\
\uparrow \text { IL-1 } 1 \beta \text { en IL-6- } \\
\text { expressie in heterofielen }\end{array}$ & (De Boever et al., 2010) \\
\hline E. coli $0128: \mathrm{B} 12$ & $2,5 \mathrm{mg} / \mathrm{dier}$ & dubbeldoel & $5 w$ & $500-650$ & IP & $\uparrow$ (piek 2 u n.t.) & - & (Johnson et al., 1993) \\
\hline E. coli $\mathrm{O} 55: \mathrm{B} 5$ & $1 \mathrm{mg} / \mathrm{kg} \mathrm{LG}$ & legkip & & $1500-2000$ & IP & - & - & (Barnes et al., 2002) \\
\hline E. coli $055: \mathrm{B} 6$ & $3 \mathrm{mg} / \mathrm{kg} \mathrm{LG}$ & vleeskip & $3 w$ & - & IP & - & $\uparrow$ IL-6 plasma & (Shen et al., 2010) \\
\hline E.coli O111:B4 & $4 \mu \mathrm{g} / \mathrm{mL}$ & macrofagen kip & & - & in vitro & - & $\begin{array}{l}\uparrow T N F-\alpha \text { (4u n.t.) gevolgd } \\
\text { door } \downarrow(18-48 \text { u n.t.) }\end{array}$ & (Hong et al., 2006) \\
\hline E. coli & $0,0015 \mathrm{mg} / \mathrm{kg} \mathrm{LG}$ & vleeskip & - & - & $\begin{array}{l}\text { IV } \\
\text { ICV }\end{array}$ & $\uparrow$ & - & (Macari et al., 1993) \\
\hline E. coli & $\begin{array}{l}0,001 \mathrm{mg} / \mathrm{kg} \mathrm{LG} \\
0,010 \mathrm{mg} / \mathrm{kg} \mathrm{LG} \\
0,1 \mathrm{mg} / \mathrm{kg} \mathrm{LG}\end{array}$ & pekingeend & - & $2400-3400$ & IV & $\begin{array}{l}\uparrow(\text { piek } 3 \text { u n.t.) } \\
\uparrow \text { (piek 4u n.t.) } \\
\uparrow \text { (piek 4,9u n.t.) }\end{array}$ & $\begin{array}{l}- \\
- \\
-\end{array}$ & (Maloney en Gray, 1998) \\
\hline E. coli & $2 \mathrm{mg} / \mathrm{kg} \mathrm{LG}$ & legkip & - & 120 & IC & - & $\uparrow$ IL-6 serum & (Nakamura et al., 1998) \\
\hline E. coli & $0,3 \mathrm{mg} / \mathrm{dier}$ & vleeskip & $4 w$ & - & $\mathrm{SC}$ & - & - & (Buyse et al., 2007) \\
\hline \multirow{4}{*}{$\begin{array}{l}\text { Salmonella } \\
\text { Typhimurium }\end{array}$} & $0,5 \mathrm{mg} / \mathrm{kg} \mathrm{LG}$ & \multirow[t]{4}{*}{ Japanse kwartel } & $18 \mathrm{~d}$ & 55 & IP & \multirow{4}{*}{$\begin{array}{l}- \\
\downarrow \text { (piek 1u n.t.) gevolgd } \\
\text { door } \uparrow(\text { piek } 10 \mathrm{u} \text { n.t.) } \\
\downarrow \text { (piek 1u n.t.) gevolgd } \\
\text { door } \uparrow(\text { (piek } 10 \mathrm{u} \text { n.t.) } \\
\uparrow \text { (piek 10u n.t.) } \\
\uparrow \text { (piek 10u n.t.) } \\
\uparrow \text { (piek 10u n.t.) } \\
\uparrow \text { (piek 5u n.t.) }\end{array}$} & - & \multirow[t]{4}{*}{ (Koutsos en Klasing, 2001) } \\
\hline & 1 mg/kg LG & & $18 \mathrm{~d}$ & 55 & IP & & - & \\
\hline & 2,5 mg/kg LG & & $18 \mathrm{~d}$ & 55 & IP & & - & \\
\hline & $\begin{array}{l}2,5 \mathrm{mg} / \mathrm{kg} \mathrm{LG} \\
7,5 \mathrm{mg} / \mathrm{kg} \mathrm{LG} \\
22,5 \mathrm{mg} / \mathrm{kg} \mathrm{LG} \\
7,5 \mathrm{mg} / \mathrm{kg} \mathrm{LG}(3 \mathrm{x})\end{array}$ & & $\begin{array}{l}23 d \\
23 d \\
23 d \\
10 d\end{array}$ & $\begin{array}{l}72 \\
72 \\
72 \\
24\end{array}$ & $\begin{array}{l}\text { IP } \\
\text { IP } \\
\text { IP } \\
\text { IP }\end{array}$ & & $\begin{array}{l}- \\
- \\
- \\
\uparrow \text { mRNA-expressie IL-1 } \\
\text { lever en milt }\end{array}$ & \\
\hline $\begin{array}{l}\text { Salmonella } \\
\text { Typhimurium }\end{array}$ & $4 \mu \mathrm{g} / \mathrm{mL}$ & macrofagen kip & - & - & in vitro & - & $\begin{array}{l}\uparrow \text { TNF- } \alpha \text { (4u n.t.) gevolgd } \\
\text { door } \downarrow(18-48 \text { u.t. })\end{array}$ & (Hong et al., 2006) \\
\hline $\begin{array}{l}\text { Salmonella } \\
\text { Typhimurium }\end{array}$ & $5 \mathrm{mg} / \mathrm{kg} \mathrm{LG}$ & vleeskip & $3 w$ & 690 & IV & - & $\uparrow$ IL-6 plasma & (Xie et al., 2000) \\
\hline $\begin{array}{l}\text { Salmonella } \\
\text { Typhimurium }\end{array}$ & $0,1-5 \mathrm{mg} / \mathrm{kg} \mathrm{LG}$ & legkip & $34 \mathrm{~d}$ & 327 & IP & $\uparrow$ (piek 4u n.t.) & $\begin{array}{l}\uparrow \mathrm{mRNA} \text {-expressie IL-1 } \\
\text { en IFN- } \gamma \text { milt }\end{array}$ & $\begin{array}{l}\text { (Leshchinsky en Klasing, } \\
\text { 2001) }\end{array}$ \\
\hline $\begin{array}{l}\text { Salmonella } \\
\text { Typhimurium }\end{array}$ & $5 \mathrm{mg} / \mathrm{kg} \mathrm{LG}$ & vleeskip & $34 d$ & 1194 & IP & $\uparrow$ (piek 12u n.t.) & $\begin{array}{l}\uparrow \mathrm{mRNA} \text {-expressie IL-1 } \beta \\
\text { en IFN- } \gamma \text { milt }\end{array}$ & $\begin{array}{l}\text { (Leshchinsky en Klasing, } \\
2001 \text { ) }\end{array}$ \\
\hline $\begin{array}{l}\text { Salmonella } \\
\text { Typhimurium }\end{array}$ & $0,0005 \mathrm{mg} /$ dier & vleeskip & $4 \mathrm{w}$ & - & IV & - & $\begin{array}{l}\uparrow \mathrm{mRNA} \text { Rexpressie IL-1 } \beta \text {, } \\
\text { IFN- } \gamma \text { en MGF milt }\end{array}$ & $\begin{array}{l}\text { (Leshchinsky en Klasing, } \\
\text { 2003) }\end{array}$ \\
\hline $\begin{array}{l}\text { Salmonella } \\
\text { Enteritidis }\end{array}$ & $4 \mu \mathrm{g} / \mathrm{mL}$ & macrofagen kip & - & - & in vitro & - & $\downarrow$ TNF- $\alpha$ (18u n.t.) & (Hong et al., 2006) \\
\hline $\begin{array}{l}\text { Salmonella } \\
\text { Minnesota }\end{array}$ & $10 \mu \mathrm{g} / \mathrm{mL}$ & $\begin{array}{l}\text { trombocyten } \\
\text { vleeskip }\end{array}$ & - & - & in vitro & - & $\begin{array}{l}\uparrow \text { mRNA-expressie IL-1 } \beta \text {, } \\
\text { IL-6, IL-12 }\end{array}$ & (Ferdous et al., 2008) \\
\hline Salmonella typhosc & $a 0,1 \mathrm{mg} / \mathrm{kg} \mathrm{LG}$ & pekingeend & - & $2400-3200$ & $\mathrm{IM}$ & $\uparrow$ (piek 6u n.t.) & & (Gray et al., 2005) \\
\hline
\end{tabular}

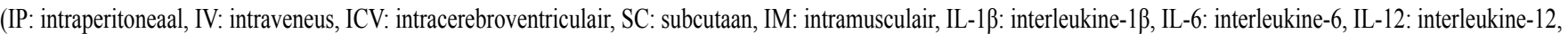
TNF- $\alpha$ : tumor necrosis factor $\alpha$, IFN- $\gamma$ : interferon- $\gamma$, MGF: myelomonocytic growth factor, n.t.: na toediening)(- = niet onderzocht $)$ 
Kyriazakas et al., 1998). De expressie van ziektegedrag wordt beïnvloed door verschillende factoren, zoals omgevingstemperatuur en seizoen. Zo is de vermindering van voedselopname meer uitgesproken bij vogels gehuisvest bij een thermoneutrale omgevingstemperatuur $\left(34^{\circ} \mathrm{C}\right)$ dan bij vogels gehuisvest bij een lagere omgevingstemperatuur $\left(15^{\circ} \mathrm{C}\right)$ (Burness et al., 2010). De gedragsveranderingen bij de mannelijke witkruingors (Zonotrichia leucophrys) in gevangenschap zijn meer uitgesproken tijdens de fokperiode dan in de winter. Dit kan verklaard worden door de grotere vetmassa tijdens de fokperiode met als gevolg een grotere energiereserve voor de ontstekingsreactie dan tijdens de winterperiode. Deze seizoensgebonden variatie in gedragsveranderingen komt niet voor bij vrouwelijke witkruingorsen (Owen-Ashley en Wingfield, 2007). Dit verschilt echter van het ziektegedrag van de wildlevende, mannelijke zanggors (Melospiza melodia morphna) die juist tijdens de winterperiode een grotere vetmassa heeft en bijgevolg duidelijkere gedragsveranderingen ondergaat als onderdeel van de ontstekingsreactie dan mannelijke dieren tijdens de fokperiode (Owen-Ashley en Wingfield, 2006). Daarnaast is het basale corticosterongehalte van mannelijke vogels tijdens de fokperiode hoger dan bij deze tijdens de winterperiode wegens een hogere energiebehoefte voor territoriaal gedrag, gonadale ontwikkeling en testosteronproductie (Ketterson et al., 1991; Ketterson en Nolan Jr., 1999). Hierdoor is er minder energie beschikbaar voor de ontstekingsreactie, zodat de vogels minder gevoelig zijn voor LPS (Owen-Ashley en Wingfield, 2006). Een hoog testosterongehalte zorgt eveneens voor een onderdrukking van de ontstekingsreactie (Wingfield, 1994).

\section{LPS-GEÏNDUCEERDE SHOCK}

De LPS-geïnduceerde ontstekingsreactie kan bij hoge dosering leiden tot endotoxine-shock of multipel orgaanfalen als gevolg van een overmatige productie van pro-inflammatoire mediatoren (onder andere TNF- $\alpha$, IL-1 $\beta$ en NO). NO zorgt voor vasodilatatie, door middel van relaxatie van vasculair glad spierweefsel en een verminderde gevoeligheid voor vasoconstrictoren. Gecombineerd met een verminderde myocardfunctie zorgt dit voor hypotensie met mogelijk shock tot gevolg. Hypotensie gaat gepaard met hypoperfusie van de weefsels, waardoor hypoxie en weefselschade kunnen optreden (Karima et al., 1999). De interactie tussen $\mathrm{NO}$ en het superoxide anion $\left(\mathrm{O}_{2}{ }^{-}\right)$ leidt tot de vorming van cytotoxische zuurstofradicalen (onder andere peroxynitriet of $\mathrm{ONOO}^{-}$en het hydroxylradicaal of $\mathrm{OH}$ ) die eveneens weefselschade veroorzaken (Beckman en Koppenol, 1996). Naast weefselschade zorgen zuurstofradicalen voor de activatie van $\mathrm{NF}-\kappa \mathrm{B}$, dat onder andere instaat voor de activatie van de productie van pro-inflammatoire cytokinen, waardoor de ontstekingsreactie verder wordt versterkt (Sen en Packer, 1996; Hierholzer et al., 1998; Karima et al., 1999). Adhesie van leukocyten aan endotheel gaat gepaard met beschadiging van de microvasculatuur, waardoor weefseloedeem optreedt en de weefselperfusie verder daalt (Golenbock et al., 1991; White et al., 1997; Chow et al, 1999; Karima et al., 1999; Lien et al., 2000). Neutrofielen zorgen na migratie door de endotheelcellaag voor de vrijstelling van zuurstofradicalen, maar stellen daarnaast ook verschillende proteasen vrij, zoals serineproteasen. Neutrofiel-elastase is een serineprotease dat zorgt voor de afbraak van verschillende eiwitten, waaronder transporteiwitten, membraaneiwitten, celreceptoren, fibronectine en collageen, maar ook fibrinolysefactoren, die een rol spelen in de afbraak van bloedklonters. De verhoogde expressie van weefselfactor en factor VIIa na LPS-toediening zorgt voor een verhoogde activatie van de stollingscascade (Levi et al., 1994; 1997) (Figuur 3). De combinatie van verhoogde stolling en verminderde fibrinolyse leidt tot de ontwikkeling van gedissemineerde intravasculaire stolling (DIC) (Karima et al., 1999). DIC is een verstoring van de hemostasebalans met verhoogde activatie van de stollingscascade en gaat gepaard met microvasculaire trombose en uitputting van stollingsfactoren, waardoor uiteindelijk bloedingen optreden met risico op multipel orgaanfalen (Johnson et al., 1998). Bepaalde stollingsfactoren, zoals trombine en factor $\mathrm{Xa}$, stimuleren de vrijstelling van pro-inflammatoire cytokinen door endotheelcellen en monocyten en versterken de ontstekingsreactie (Karima et al., 1999). Dit mechanisme, zoals het verloopt bij zoogdieren, is bij vogels nog niet volledig opgehelderd.

Vogels zijn minder gevoelig voor de ontwikkeling van endotoxine-shock dan zoogdieren. Dit is het gevolg van verschillen in het stollingsmechanisme en het activatiemechanisme van interferon $\beta$ (IFN- $\beta$ ). Het stollingsmechanisme van zoogdieren bestaat uit een intrinsieke en extrinsieke cascade die beide nodig zijn voor de vorming van trombine dat de gemeenschappelijke stollingscascade activeert tot de vorming van de uiteindelijke bloedklonter (Figuur 3). De intrinsieke stollingscascade is bij kippen en struisvogels zwak vergeleken met zoogdieren en bepaalde onderdelen van de extrinsieke stollingscascade, zoals stollingsfactor VII, zijn beperkt tot niet aanwezig. Hierdoor verloopt de stollingscascade trager bij vogels dan bij zoogdieren (Frost et al., 1999). Stollingsfactor X, die een sleutelrol speelt in de vorming van trombine, is bij kippen echter wel aanwezig (Stopforth, 1970) en werd eveneens bij struisvogels aangetoond (Frost et al., 1999). Fibrinolyse gebeurt bij vogels even efficiënt als bij zoogdieren (Frost et al., 1999). Deze verschillen met zoogdieren kunnen, door een kleinere kans op DIC, verklaren waarom vogels resistenter zijn tegen de hemodynamische LPS dan zoogdieren (Adler en DaMassa, 1979).

IFN- $\beta$ zorgt voor de productie van chemokinen en adhesiemoleculen die een rol spelen bij inflam- 
matie (Shimizu et al., 1990; Sikorski et al., 2011). Verschillen in het activatiemechanisme van IFN- $\beta$ tussen zoogdieren en vogels uiten zich in de afwezigheid van de signaaltransductie tussen TLR4, Toll/IL-1 receptor-domein bevattend adaptoreiwit (TRIF) en TRIF-gerelateerde adaptoreiwit (TRAM) na binding met LPS bij vogels (Berczi et al., 1966; Keestra en Van Putten, 2008). De afwezigheid van IFN- $\beta$ zorgt bij muizen voor resistentie tegenover LPS-geïnduceerde endotoxine shock (Karaghiosoff et al., 2003). Bij vissen, die een hoge resistentie hebben tegenover endotoxine-shock, is deze signaaltransductie eveneens afwezig (Iliev et al., 2005).

\section{CONCLUSIE}

Door middel van LPS-inflammatiemodellen wordt er bij verschillende diersoorten een ontstekingsreactie opgewekt die gepaard gaat met veranderingen op cellulair niveau, fysiologische en gedragsveranderingen. De veranderingen die optreden bij vogels verschillen van deze bij zoogdieren. Zo speelt TNF- $\alpha$ bij zoogdieren een belangrijke rol bij inflammatie, terwijl bij vogels vooral TL1A van belang is en TNF- $\alpha$ enkel nog maar in vitro werd aangetoond. Daarnaast treedt er bij zoogdieren, zoals de hond, de muis, de rat, de cavia en de kat, onafhankelijk van de diersoort, koorts op na intraveneuze toediening van LPS (LeMay et al., 1990; Long et al., 1990; Kozak et al, 1994; Roth et al., 2002; McCann et al., 2005), terwijl dit niet altijd het geval is bij vogels. De gevoeligheid voor LPS verschilt eveneens tussen zoogdieren en vogels. Zo is er een veel hogere dosis LPS nodig om een ontstekingsreactie op te wekken bij kippen $(1 \mathrm{mg} / \mathrm{kg}$ lichaamsgewicht of LG) dan bij kalveren $(0,5 \mu \mathrm{g} / \mathrm{kg} \mathrm{LG})$ en varkens $(15$ $\mu \mathrm{g} / \mathrm{kg} \mathrm{LG}$ ) (De Boever et al., 2008; Wyns et al., 2014; Plessers et al., 2015). Deze verschillen zijn onder andere het gevolg van een mobiliteitsverschil van CD14, waarbij dit eiwit minder mobiel is in de celmembraan van kippen dan in die van zoogdieren. Bijgevolg kan er minder activatie van de cel optreden na vorming van het CD14:LPS-complex. Tevens is er een sterk verschil in de lichaamsbouw van zoogdieren en vogels. Zo is de lichaamsoppervlakte-volumeratio hoger bij vogels dan bij zoogdieren, waardoor er bij vogels meer warmteverlies optreedt dan bij zoogdieren. Dit kan resulteren in hypothermie tijdens de ontstekingsreactie, voornamelijk bij Passeriformen. Daarnaast is de gemiddelde lichaamstemperatuur van Passeriformen relatief hoog $\left(41^{\circ} \mathrm{C}\right)$, waardoor elke bijkomende temperatuurverhoging door een verhoogd metabolisme moeilijk is, aangezien het metabolisme voor elke stijging van de lichaamstemperatuur met $1{ }^{\circ} \mathrm{C}$ moet verhogen met 10\% (Kluger, 1979; Owen-Ashley en Wingfield, 2007).

Door onderzoek naar de aan- of afwezigheid van veranderingen gerelateerd aan de ontstekingsreactie en naar de omvang ervan, kunnen LPS-inflammatiemodellen toegepast worden in onder andere farmaco- dynamiekstudies. Hiermee kan het effect van antiinflammatoire geneesmiddelen, zoals NSAIDs, op de ontstekingsreactie en bijgevolg de klinische relevantie worden nagegaan. Daarnaast kunnen deze modellen ook ingezet worden om de immunomodulerende eigenschappen van andere klassen farmaca te bestuderen, zoals de macrolide antibiotica.

\section{REFERENTIES}

Adler H.E., DaMassa A.J. (1979). Toxicity of endotoxin to chicks. Avian Diseases 23, 174-178.

Baert K., Duchateau L., De Boever S., Cherlet M., De Backer P. (2005a). Antipyretic effect of oral sodium salicylate after an intravenous $E$. coli LPS injection in broiler chickens. British Poultry Science 46, 137-143.

Baert K., De Boever S., Duchateau L., De Backer P. (2005b) Sodium salicylate attenuates lipopolysaccharide (LPS)induced adipsia, but not hypophagia, in broiler chickens. British Poultry Science 46, 144-148.

Bauerle P.A., Henkel T. (1994). Function and activation of $\mathrm{NF}-\kappa \mathrm{B}$ in the immune system. Annual Review of Immunology 12, 141-79.

Barnes D.M., Song Z., Klasing K.C., Bottje W. (2002). Protein metabolism during an acute phase response in chickens. Amino Acids 22, 15-26.

Bayyari G.R., Huff W.E., Rath N.C., Balog J.M., Newberry L.A., Villines J.D., Skeeles J.K. (1997). Immune and physiological responses of turkeys with green-liver osteomyelitis complex. Poultry Science 76, 280-288.

Beckman J.S., Koppenol W.H. (1996) Nitric oxide, superoxide and peroxynitrite: the good, the bad, and ugly. American Journal of Physiology 271, 1424-1437.

Berczi I., Bertok L., Bereznai T. (1966). Comparative studies on the toxicity of Escherichia coli lipopolysaccharide endotoxin in various animal species. Canadian Journal of Microbiology 12, 1070-1071.

Branco L.G.S., Soriano R.N., Steiner A.A. (2014). Gaseous mediators in temperature regulation. Comprehensive Physiology 4, 1301-1338.

Burness G., Armstrong C., Fee T., Tilman-Schindel E. (2010). Is there an energetic-based trade-off between thermoregulation and the acute phase response in zebra finches? Journal of Experimental Biology 213, 13861394.

Buyse J., Swennen Q., Niewold T.A., Klasing K.C., Janssens G.P.J., Baumgartner M., Boddeeris. B.M. (2007). Dietary L-carnitine supplementation enhances the lipopolysaccharide-induced acute phase protein respone in broiler chickens. Veterinary Immunology and Immunopathology 118, 154-159.

Byrnes S., Eaton R., Kogut M. (1992). In vitro interleukin-1 and tumor necrosis factor- $\alpha$ production by macrophages from chickens infected with either Eimeria maxima or Eimeria tenella. International Journal of Parasitology 23, 639-45.

Chamanza R., Toussaint M.J.M., van Ederen A.M., van Veen L., Hulskamp-Koch C., Fabri T.H.F. (1999). Serum amyloid $\mathrm{A}$ and transferring in chicken. A preliminary investigation of using acute-phase variables to assess diseases in chickens. Veterinary Quarterly 21, 158-162.

Chow J., Young D., Golenbock D., Christ W., Gusovsky F. (1999). Toll-like receptor-4 mediates lipopolysaccharide- 
induced signal transduction. The Journal of Biological Chemistry 274, 10689-10692.

Curtis M.J., Butler E.J. (1980). Response of ceruloplasmin to Escherichia coli endotoxins and adrenal hormones in the domestic fowl. Research in Veterinary Science 28, 217-222.

Dantonio V., Batalhão M.E., Fernandes M.H., Komegae E.N., Buqui G.A., Lopes N.P. et al. (2016). Nitric oxide and fever: immune-to-brain signaling vs. thermogenesis in chicks. American Journal of Physiology-Regulatory, Integrative and Comparative Physiology 310, 896-905.

De Boever S., Beyaert R., Vandemaele F., Baert K., Duchateau L., Goddeeris B., De Backer P., Croubels S. (2008). The influence of age and repeated lipopolysaccharide administration on body temperature and the concentration of interleukin-6 and IgM antibodies against lipopolysaccharide in broiler chickens. Avian Pathology 37, 39-44.

De Boever S., Croubels S., Meyer E., Sys S., Beyaert R., Ducatelle R., De Backer P. (2009). Characterization of an intravenous lipopolysaccharide inflammation model in broiler chickens. Avian Pathology 38, 403-411.

De Boever S., Neirinckx E.A., Meyer E., De Baere S., Beyaert R., De Backer P., Croubels S. (2010). Pharmacodynamics of tepoxalin, sodium-salicylate and ketoprofen in an intravenous lipopolysaccharide inflammation model in broiler chickens. Journal of Veterinary Pharmacology and Therapeutics 33, 564-572.

Digby M.R., Lowenthal J.W. (1995). Cloning and expression of the chicken interferon- $\gamma$ gene. Journal of Interferon and Cytokine Research 15, 939-945.

Dil N., Qureshi M.A. (2002). Involvement of lipopolysaccharide related receptors and nu-clear factor kappa B in differential expression of inducible nitric oxide synthase in chicken macrophages from different genetic backgrounds. Veterinary Immunology and Immunopathology 88, 149-161.

Doyle S.L., O’Neill L.A. (2006). Toll-like receptors: from the discovery of NF- $\kappa$ B to new insights into transcriptional regulations in innate immunity. Biochemical Pharmacology 72, 1102-1113.

Durum S.K., Oppenheim J.J., Neta, R. (1990). Immunophysiologic role of interleukin 1. In: J.J. Oppenheim, E.M. Shevach (editors). Immunophysiology: the Role of Cells and Cytokines in Immunity and Inflammation. Oxford University Press, New York, 210-225.

Fajardo L.F. (1984). Pathological effects of hyperthermia in normal tissues. Cancer Research 44, 4826-4835.

Ferdous F., Maurice D., Scott T. (2008). Broiler chick thrombocyte response to lipopolysaccharide. Poultry Science 87, 61-63.

Fraifeld V., Blaicher-Kulick R., Degen A., Kaplanski J. (1995). Is hypothalmic prostaglandin $\mathrm{E}_{2}$ involved in avian fever? Life Sciences 56, 1343-1346.

Frafield V., Kaplanski J. (1998). Brain eicosanoids and LPS fever: species and age differences. Progress in Brain Research 115, 141-146.

Frost C.L., Naudé R.J., Oelofsen W., Jacobson B. (1999). Comparative blood coagulation studies in the ostrich. Immunopharmacology 45, 75-81.

Geller, D.A., Nussler A.K., Di Silvio M., Lowenstein C.J., Shapiro R.A., Wang S.C. (1993). Cytokines, endotoxin, and glucocorticoids regulate the expression of inducible nitric oxide synthase in hepatocytes. In: Proceedings of the National Academy of Sciences USA 90, 522-526.

Goetz F.W., Planas J.V., MacKenzie S. (2004). Tumor ne- crosis factors. Developmental and comparative Immuno$\log y$ 28, 487-497.

Golenbock D., Hampton R., Qureshi N., Takayama K., Raetz C. (1991). Lipid A-like mole-cules that antagonize the effects of endotoxins on human monocytes. The Journal of Biological Chemistry 266, 19490-19498.

Gore I., Isaacson N.H. (1949). The pathology of hyperpyrexia. American Journal of Pathology 25, 1029-1060.

Gray D.A., Maloney S.K., Kamerman P.R. (2005). Lipopolysaccharide-induced fever in Pekin ducks is mediated by prostaglandins and nitric oxide and modulated by adrenocortical hormones. American Journal of Physiology-Regulatory, Integrative and Comparative Physiology 289, 1258-1264.

Harmon B.G. (1998). Avian heterophils in Inflammation and disease resistance. Poultry Science 77, 972-977.

Hart B.L. (1988). Biological basis of the behaviour of sick animals. Neuroscience and Behavioural Reviews 12, 151-158.

Haudek S.B., Natmessing B.E., Fürst W., Bahrami S., Schlag G., Redl H. (2003). Lipopolysaccharide dose response in baboons. Shock 20,431-436.

Heinrich P.C., Castelli J.V., Andus T. (1990). Interleukin-6 and the acute phase response. Biochemical Journal 265, 621-636.

Hierholzer C., Harbrecht B., Menezes J.M., Kane J., MacMicking J., Nathan C.F. (1998). Essential role of induced nitric oxide in the initiation of the inflammatory response after hemorrhagic shock, Journal of Experimental Medicine 187, 917-928

Holst O. (2007). The structure of core regions from enterobacterial lipopolysaccharide - an update. FEMS Microbiology Letters 271, 3-11.

Hong Y.H., Lillehoj H.S., Lee S.H., Park D.W., Lillehoj E.P. (2006). Molecular cloning and characterization of chicken lipopolysaccharide-induced TNF- $\alpha$ factor (LITAF). Developmental and Comparative Immunology 30, 919-929.

Iliev D.B., Roach J.C., Mackenzie S., Planas J.V., Goetz F.W. (2005). Endotoxin recognition: in fish or not in fish? FEBS Letters 579, 6519-6528.

Inoue M., Satoh W., Murakami H. (1997). Plasma alpha1acid glycoprotein in chickens infected with infectious bursal disease virus. Avian Diseases 41, 164-170.

Jakowlew S.B., Dillard P.J., Sporn M.B., Roberts A.B. (1988). Nucleotide sequence of chicken transforming growth factor-beta 1 (TGF- $\beta$ 1). Nucleic Acids Research 16,8730 .

Jakowlew S.B., Dillard P.J., Sporn M.B., Roberts A.B. (1990). Complementary deoxyribonucleic acid cloning of an mRNA encoding transforming growth factor- $\beta 2$ from chicken embryo chondrocytes. Growth Factors 2, 123-133.

Jerala R. (2007). Structural biology of the LPS recognition. International Journal of Medical Microbiology 29, 353363.

Johnson R.W., Curtis S.E., Dantzer R., Kelley K.W. (1993) Central and peripheral prostaglandins are involved in sickness behavior in birds. Physiology \& Behavior 53, 127-131.

Johnson K., Choi Y., DeGroot E., Samuels I., Creasey A., Aarden L. (1998). Potential mechanisms for a proinflammatory vascular cytokine response to coagulation activation. Journal of Immunology 160, 5130-5135.

Jones C.A., Edens F.W., Denbow D.M. (1983). Influence of age on the temperature response of chickens to Esche- 
richia coli and Salmonella typhimurium endotoxins. Poultry Science 62, 1553-1558.

Kaiser P., Poh T.Y., Rothwell L., Avery S., Balu S., Pathania U.S. et al. (2005). A genomic analysis of chicken cytokines and chemokines. Journal of Interferon and Cytokine Research 25, 467-484.

Karaghiosoff M., Steinborn R., Kovarik P., Kriegshäuser G., Baccarini M., Donabauer, B. (2003). Central role for type I interferons and Tyk2 in lipopolysaccharide-induced endotoxin shock. Nature Immunology 4, 471-477.

Karima R., Matsumoto S., Higashi H., Matsushima K. (1999). The molecular pathogenesis of endotoxic shock and organ failure. Molecular Medicine Today 5, 123-132

Keestra A.M., Van Putten J.P.M. (2008). Unique properties of the chicken TLR4/MD-2 complex: selective lipopolysaccharide activation of the MyD88-dependent pathway. Journal of Immunology 181, 4354-4362

Ketterson E.D., Nolan Jr. V. (1999). Adaptation, exaptation, and constraint: a hormonal perspective. American Naturalist 154, 4-25.

Ketterson E.D., Nolan V., Wolf L., Ziegenfus C., Dufty A.M., Ball G.F., (1991). Testosterone and avian life histories: the effect of experimentally elevated testosterone on corticosterone and body mass in dark-eyed juncos. Hormones and Behavior 25, 489-503.

Klasing K.C. (1984). Effect of inflammatory agents and interleukin 1 on iron and zinc metabolism. American Journal of Physiology 247, 901-904.

Klasing K.C., Humphrey B.D., Mireles A.J., Koutsos E.A. (2004). What are the costs of immunity? Journal of Dairy Science 87, 444.

Kluger M.J. (1979) Fever. Its Biology, Evolution and Function. Princeton University Press, Princeton.

Kluger M.J. (1986). Is fever beneficial? The Yale Journal of Biology and Medicine 59, 89-95.

Kluger M.J. (1991). Fever: role of pyrogens and cryogens. Physiological Reviews 71, 93-127.

Kogut M., Haiqi H., Kaiser P. (2005). Lipopolysaccharide binding protein/CD14/TLR4-dependent recognition of salmonella LPS induces the functional activation of chicken heterophils and up-regulation of pro-inflammatory cytokine and chemokine gene expression in these cells. Animal Biotechnology 14, 165-181.

Kogut M.H., Moyes R., Deloach J.R. (1997). Neutralization of G-CSF inhibits ILK-induced heterophil influx: granulocyte-colony stimulating factor mediates the Salmonella enteritidis-immune lymphokine potentiation of the acute avian inflammatory response. Inflammation 21, 9-25.

Koh T.S., Peng R.K., Klassing K.C. (1996). Dietary copperlevel affects copper metabolism during lipopolysaccharide induced immunological stress in chicks. Poultry Science 75, 867-872.

Koskela K., Nieminen P., Kohonen P., Salminen H., Lassila O. (2004). Chicken B-cell-activating factor: regulator of B-cell survival in the bursa of fabricius. Scandinavian Journal of Immunology 59, 449-457.

Koutsos E.A., Klasing K.C. (2001). The acute phase response in Japanese quail (Coturnix coturnix japonica). Comparative Biochemistry and Physiology Part C 128, 255-263.

Kozak W.I.E.S., Conn C.A., Kluger M.J. (1994). Lipopolysaccharide induces fever and depresses locomotor activity in unrestrained mice. American Journal of Physiology-Regulatory, Integrative and Comparative Physiology
$266,125-135$

Kumar V., Abbas A.K., Aster J.C. (2015). Inflammation and repair. In: Robbins and Cotran (editors). Pathologic Basis of Disease. Negende editie, Saunders, Philadelphia, 69-112.

Kushner I. (1982). The phenomenon of the acute phase response. Annals of the New York Academy of Sciences 389, 39-48.

Kyriazakas I., Tolkamp B.J., Hutchings M.R. (1998). Towards a functional explanation for the occurrence of anorexia during parasitic infections. Animal Behaviour 56, 265-274.

Langhans W. (2000). Anorexia of infection: current prospects. Nutrition 16, 996-1005.

LeMay L.G., Vander A.J., Kluger M.J. (1990). Role of interleukin 6 in fever in rats. American Journal of Physiology 258, 798-803.

Lees P., May S., McKellar Q. (1991). Pharmacology and therapeutics of nonsteroidal anti-inflammatory drugs in the dog and cat. Journal of Small Animal Practice 32, 183-193.

Leshchinsky T.V., Klasing K.C. (2001). Divergence of the inflammatory response in two types of chickens. Developmental \& Comparative Immunology 25, 629-638.

Leshchinsky T.V., Klasing K.C. (2003). Profile of chicken cytokines induced by lipopolysaccharide is modulated by dietary alpha-tocopheryl acetate. Poultry Science 82, 1266-1273.

Levi M., ten Cate H., Bauer K.A., Van der Poll T., Edgington T.S., Büller H.R. (1994). Inhibition of endotoxininduced activation of coagulation and fibrinolysis by pentoxifylline or by a monoclonal anti-tissue factor antibody in chimpanzees. Journal of Clinical Investigation 93, 114-120.

Levi M., Van der Poll T., ten Cate H., van Deventer S. (1997). The cytokinemediated imbalance between coagulant and anti-coagulant mechanisms in sepsis and endotoxaemia. European Journal of Clinical Investigation 27, 3-9.

Lien E., Means T., Heine H., Yoshimura A., Kusumoto S., Fukase K. (2000). Toll-like receptor 4 imparts ligandspecific recognition of bacterial lipopolysaccha-ride. The Journal of Clinical Investigation 105, 497-504.

Lillehoj H.S., Kaspers B., Jenkins M.C., Lillehoj E.P. (1992). Avian interferon and interleukin-2: a review by comparison with mammalian homologues. Poultry Science Reviews 4, 67-85.

Long N.C., Otterness I., Kunkel S.L., Vander A.J., Kluger M.J. (1990). Roles of interleukin 1 beta and tumor necrosis factor in lipopolysaccharide fever in rats. American Journal of Physiology 259, 724-728.

Lüderitz O., Freudenberg M.A., Galanos C., Lehmann V., Rietschel E.T., Shaw D. (1982). Lipopolysaccharides of Gram-negative bacteria. Current Topics in Membranes and Transport 17, 79-151.

Macari M., Furlan R.L., Gregorut F.P., Secato E.R., Guerreiro J.R. (1993). Effects of endotoxin, interleukin-1 and prostaglandin injections on fever response in broilers. British Poultry Science 34, 1035-1042.

Malamud N., Haymaker W., Custer R.P. (1946). Heat stroke. A clinico-pathologic study of 125 fatal cases. Military Surgeon 99, 397-449.

Maloney S.K., Gray D.A. (1998). Characteristics of the febrile response in Pekin ducks. Journal of Comparative Physiology B 168, 177-182. 
Mayeux P. (1997). Pathobiology of lipopolysaccharide. Journal of Toxicology and Environmental Health 51, 415-435.

McCann M.E., Rickes E.L., Hora D.F., Cunningham P.K., Zhang D., Brideau C. (2005). In vitro effects and in vivo efficacy of a novel cyclooxygenase- 2 inhibitor in cats with lipopolysaccharide-induced pyrexia. American Journal of Veterinary Research 66, 1278-1284.

Moore, J.N., Barton, M.H. (1998). An update on endotoxaemia. Equine Veterinary Education 10, 300-306.

Morimoto A., Murakami N., Nakamori T., Watanabe T. (1987). Evidence for separate mechanisms of induction of biphasic fever inside and outside the blood-brain barrier in rabbits. Journal of Physiology 383, 629-637.

Morrison D.C., Ulevitch R.J. (1978). The effect of bacterial endotoxin on host mediation systems. A review. American Journal of Pathology 93, 527-601.

Murata H., Shimada N., Yoshioka M. (2004). Current research on acute phase proteins in veterinary diagnosis: an overview. Veterinary Journal 168, 28-40.

Nagashima T., Ohinata H., Kuroshima A. (1994). Involvement of nitric oxide in noradrenaline-induced increase in blood flow through brown adipose tissue. Life Sciences $54,17-25$.

Nakamura K., Mitarai Y., Koizumi N., Shibahara T., Nakajima Y. (1998) Serum levels of interleukin-6, a1-acid glycoprotein and corticosterone in two-week-old chickens inoculated with Escherichia coli lipopolysaccharide. Poultry Science 77, 908-911.

Netea, M., Kullberg, B., Van der Meer, J. (2000). Circulating cytokines as mediators of fever. Clinical Infectious Diseases 31, 178-184.

Owen-Ashley N.T., Wingfield J.C. (2006). Seasonal modulation of sickness behavior in free-living northwestern song sparrows (Melospiza melodia morphna). Journal of Experimental Biology 209, 3062-3070.

Owen-Ashley N.T., Wingfield J.C. (2007). Acute phase responses of passerine birds: characterization and seasonal variation. Journal of Ornithology 148, 583-591.

Park, S. S., Lillehoj H. S., Hong Y. H., Lee. S. H. (2007). Functional characterization of tumor necrosis factor superfamily 15 (TNFSF15) induced by lipopolysaccharides and Eimeria infection. Developmental and Comparative Immunology 31, 934-944.

Plata-Salamán C.R. (1996). Anorexia during acute and chronic disease. Nutrition 12, 69-78.

Plessers E., Wyns H., Watteyn A., Pardon B., De Backer P., Croubels S. (2015). Characterization of an intravenous lipopolysaccharide inflammation model in calves with respect to the acute-phase response. Veterinary Immunology and Immunopathology 163, 46-56.

Raetz C., Brozek K., Clementz T., Coleman J., Galloway S., Golenbock D. (1988). Gram-negative endotoxin: A biologically active lipid. Cold Spring Harbor Symposia on Quantitative Biology LIII, 973-982.

Ramadori G., Meyer zum Buschenfelde K.H., Tobias P.S., Mathison R.J. (1990). Biosynthesis of lipopolysaccharide-binding protein in rabbit hepatocytes. Pathobiology 58, 89-94.

Rautenschlein S., Subramanian A., Sharma J.M. (1999). Bioactivities of a tumour necrosis-like factor released by chicken macrophages. Developmental and Comparative Immunology 23, 629-640.

Rietschel E., Kirikae T., Schade F., Mamut U., Schmidt G., Loppnow H. (1994). Bacterial endotoxin: molecular re- lationship of structure to activity and function. FASEB Journal 8, 217-225.

Rietschel E., Kirikae T., Schade F., Ulmer A., Holst O., Brade H. (1993). The chemical structure of bacterial endotoxin in relation to bioactivity. Immunobiology 187 , 169-190.

Roth J., Hübschle T., Pehl U., Ross G., Gerstberger R. (2002). Influence of systemic treatment with cyclooxygenase inhibitors on lipopolysaccharide-induced fever and circulating levels of cytokines and cortisol in guineapigs. Pflügers Archiv European Journal of Physiology 443, 411-417.

Rothwell L., Young J.R., Zoorob R., Whittaker C.A., Hesketh P., Archer A. (2004). Cloning and characterization of chicken IL-10 and its role in de immune response to Eimeria maxima. Journal of Immunology 173, 26752682.

Sass G., Heinlein S., Agli A., Bang R., Schümann J., Tiegs G. (2002). Cytokine expression in three mouse models of experimental hepatitis. Cytokine 19, 115-120.

Schneider K., Kothlow A., Schneider P., Tardivel A., Göbel T., Kaspers B. (2004). Chicken BAFF - a highly conserved cytokine that mediates B cell survival. International Immunology 16, 139-148.

Schneider K., Klaas R., Kaspers B., Staeheli P. (2001). Chicken interleukin-6 cDNA structure and biological properties. European Journal of Biochemistry 268, 4200-4206.

Schumann R.R., Leong S.R., Flaggs G.W., Gray P.W., Wright S.D., Mathison J.C, Tobias P.S., Ulevitch R.J. (1990). Structure and function of lipopolysaccharide binding protein. Science 249, 1429.

Sen C., Packer L. (1996). Antioxidant and redox regulation of gene transcription. FASEB Journal 10, 709-720.

Shen Y.B., Piao X.S., Kim S.W., Wang L., Liu P. (2010). The effects of berberine on the magnitude of the acute inflammatory response induced by Escherichia coli lipopolysaccharide in broiler chickens. Poultry Science 89, 13-19.

Sherwin J. E., Sobenes J.R. (1996). Liver function. In: L.A. Kaplan, A.J. Pesce (editors). Clinical Chemistry: Theory, Analysis, Correlation. Derde editie, Mosby-Year Book Inc., St. Louis, 505- 527.

Shimizu H., Mitomo K., Watanabe T., Okamoto S., Yamamoto K. (1990). Involvement of a NF-kappa B-like transcription factor in the activation of the interleukin- 6 gene by inflammatory lymphokines. Molecular and cellular biology 10, 561-568.

Sikorski K., Czerwoniec A., Bujnicki J.M., Wesoly J., Bluyssen H.A. (2011). STAT1 as a novel therapeutical target in pro-atherogenic signal integration of IFN $\gamma$, TLR4 and IL-6 in vascular disease. Cytokine \& Growth Factor Reviews 22, 211-219.

Skarnes R.C., Brown S.K., Hull S.S. en McCracken J.A. (1981). Role of prostaglandin $\mathrm{E}$ in the biphasic fever response to endotoxin. The Journal of Experimental Medicine 154, 1212-1224.

Sköld-Chiriac S., Nord A., Tobler M, Nilsson J.Å., Hasselquist D. (2015). Body temperature changes during simulated bacterial infection in a songbird fever at night and hypothermia during the day. Journal of Experimental Biology 218, 2961-296

Song K.D., Lillehok H.S., Choi K.D., Zarlenga D., Han J.Y. (1997). Expression and functional characterization of recombinant chicken interferon-gamma. Veterinary 
Immunology and Immunopathology 58, 321-333.

Steiner A.A., Branco L.G.S. (2001). Nitric oxide in the regulation of body temperature and fever. Journal of Thermal Biology 26, 325-330.

Steiner A.A., Rudaya A.Y., Ivanov A.I., Romanovsky A.A. (2004). Febrigenic signaling to the brain does not involve nitric oxide. British Journal of Pharmacology 141, 204 213.

Stopforth A. (1970). A study of coagulation mechanisms in domestic chickens. Journal of Comparative Pathology 80, 525-533.

Takahashi K., Miyake N., Ohta T., Akiba Y., Tamura K. (1998). Changes in plasma $\alpha 1$-acid glycoprotein concentration and selected immune response in broiler chickens in-jected with Escherichia coli lipopolysaccharide. British Poultry Science 39, 153-155.

Takimoto, T., Sato, K., Akiba, Y., Takahashi, K. (2008). Role of chicken TL1A on inflammatory responses and partial characterization of its receptor. The Journal of Immunology 180, 8327-8332.

Tobias P.S., Soldau K., Ulevitch R.J. (1986). Isolation of a lipopolysaccharide-binding acute phase reactant from rabbit serum. Journal of Experimental Medicine 164, 777-793.

Tobias P., Tapping R., Gegner J. (1999). Endotoxin interactions with lipopolysaccharideresponsive cells. Clinical Infectious Diseases 28, 476-481.

Todar K. (2006). Todar's Online Textbook of Bacteriology. University of Wisconsin-Madison.

Weining K.C., Sick C., Kaspers B., Staeheli P. (1998). A chicken homolog of mammalian interleukin-1 $\beta$ : cDNA cloning and purification of active recombinant protein. European Journal of Biochemistry 258, 994-1000.
White K., Kaltashov I., Cotter R., Raetz C (1997). A mono-functional 3-deoxy-D-manno-octulosonic acid (Kdo) transferase and a Kdo kinase in extracts of Haemophilus influenzae. The Journal of Biological Chemistry 272, 16555-16563.

Wingfield J.C. (1994). Regulation of territorial behavior in the sedentary song sparrow, Melospiza melodia morphna. Hormonal Behaviour 28, 1-15.

Witkamp R., Monshouwer M. (2002). Signal transduction in inflammatory processes, cur-rent and future therapeutic targets: a mini review. The Veterinary Quarterly 22, 11-16.

Wright A., Kanegasaki S. (1971). Molecular aspects of lipopolysaccharides. Physiological Reviews 4, 748-784.

Wu Z., Rothwell L., Hu T., Kaiser P. (2009). Chicken CD14, unlike mammalian CD14, is trans-membrane rather than GPI-anchored. Developmental and Comparative Immunology 33, 97-104.

Wyns H., Meyer E., Plessers E., Watteyn A., van Bergen T., Schauvliege S., De Baere S., Devreese M., De Backer P., Croubels S. (2014) Modulation of gamithromycin and ketoprofen on in vitro and in vivo porcine lipopolysaccharide-induced inflammation. Veterinary Immunology and Immunopathology 168, 211-222.

Xie H., Huff G.R., Huff W.E., Balog J.M., Holt P., Rath N.C. (2002). Identification of ovotransferrin as an acute phase protein in chickens. Poultry Science 81, 112-120.

Xie H., Rath N.C., Huff G.R., Huff W.E., Balog J.M. (2000). Effects of Salmonella Typhimurium lipopolysaccharide on broiler chickens. Poultry Science 70, 33-40. 